\title{
Impact of warming climate and cultivar change on maize phenology in the last three decades in North China Plain
}

\author{
Dengpan Xiao ${ }^{1,2}$ - Yongqing $\mathrm{Qi}^{2}$ • Yanjun Shen ${ }^{2}$. \\ Fulu Tao $^{3}$ • Juana P. Moiwo ${ }^{3}$. Jianfeng Liu ${ }^{1}$. \\ Rede Wang ${ }^{1} \cdot$ He Zhang $^{3} \cdot$ Fengshan Liu $^{4}$
}

Received: 26 December 2014 / Accepted: 30 March 2015 /Published online: 16 April 2015

(C) Springer-Verlag Wien 2015

\begin{abstract}
As climate change could significantly influence crop phenology and subsequent crop yield, adaptation is a critical mitigation process of the vulnerability of crop growth and production to climate change. Thus, to ensure crop production and food security, there is the need for research on the natural (shifts in crop growth periods) and artificial (shifts in crop cultivars) modes of crop adaptation to climate change. In this study, field observations in 18 stations in North China Plain (NCP) are used in combination with Agricultural Production Systems Simulator (APSIM)-Maize model to analyze the trends in summer maize phenology in relation to climate change and cultivar shift in 1981-2008. Apparent warming in most of the investigated stations causes early flowering and maturity and consequently shortens reproductive growth stage. However, APSIM-Maize model run for four representative stations suggests that cultivar shift delays maturity and thereby prolongs reproductive growth (flowering to maturity)

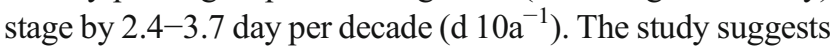
a gradual adaptation of maize production process to ongoing climate change in NCP via shifts in high thermal cultivars and
\end{abstract}

Fulu Tao

taofl@igsnrr.ac.cn

1 Institute of Geographical Sciences, Hebei Academy of Sciences, Shijiazhuang 050011, Hebei, China

2 Center for Agricultural Resources Research, Institute of Genetics and Developmental Biology, Chinese Academy of Sciences, Shijiazhuang 050021, Hebei, China

3 Institute of Geographical Sciences and Natural Resources Research, Chinese Academy of Sciences, Beijing 100101, China

4 Juncao Research Institute, Fujian Agriculture and Forestry University, Fuzhou 350002, Fujian, China phenological processes. It is concluded that cultivation of maize cultivars with longer growth periods and higher thermal requirements could mitigate the negative effects of warming climate on crop production and food security in the NCP study area and beyond.

\section{Introduction}

There is now a general consensus in the scientific community regarding warming climatic conditions in recent decades (IPCC 2013), which is considered to significantly influence phenological development and productivity of crops (Tao et al. 2006; Craufurd and Wheeler 2009; Lobell et al. 2011; Maddonni 2012). Moreover, phenological changes are vital indicators of changes in climate and environmental conditions (Orlandi et al. 2005; Xiao et al. 2013a). Obvious reductions in the length of crop growth seasons due to warming climate are extensively documented in several studies (Porter 2005; Tao et al. 2006; Estrella et al. 2009; Tao and Zhang 2010; Zhang et al. 2013; Xiao et al. 2013a, b). Other studies have noted that climate change accelerates crop growth processes, with direct negative impact on crop yield (Liu et al. 2013; Xiao and Tao 2014).

In spite of this, adaptation measures such as cultivar shifts and management improvements could reduce the negative effects of warming climate on crop production (Liu et al. 2010; Olesen et al. 2011; Wang et al. 2012). For example, the adoption of cultivars with longer growth periods could increase yield under climate change due to higher heat accumulation (Wang et al. 2012; Liu et al. 2013; Xiao and Tao 2014). Crop phenological processes are driven by the combined effects of climate variability and agronomic factors such as cultivar shifts and management practices, which are to 
some extent controlled by man (Liu et al. 2010; Xiao and Tao 2014). On this basis, there is the need to continuously study the potential application of adaptation practices in developing strategies to cope with the risks posed by climate change (Tao and Zhang 2010; Olesen et al. 2011).

The North China Plain (NCP), where winter wheat (Triticum aestivum L.) and summer maize (Zea mays L.) for the typical cropping system, is a major agrarian base in China (Tao et al. 2006). Over $50 \%$ of China's wheat and about $33 \%$ of its maize are produced in the NCP region (Wang et al. 2012), which is critical for food security and social stability in the country. Despite its importance, the region remains vulnerable to rising temperature, climate change, and water shortage (Mo et al. 2009).

Maize, the dominant crop in the region, is the most vulnerable to climate variability and climate change among cultivated staple food crops in NCP. Tao and Zhang (2010) documented that without adaptation measures, maize yield in NCP could decrease on the average by 13.2-19.1\%. Chen et al. (2012) noted an increasing effect of climate change on maize yield in the past 50 years in the area of the NCP under Shandong Province. The effects of production factors (e.g., climate change and adaptation options) are not conclusive in terms of maize phenology. Relatively, few studies have investigated the impacts of cultivar shift on maize phenology in NCP under global warming. There is therefore the need to further clarify the extent of the effects of climate change and cultivar shift on maize phenology in the region.

Thus, this study investigates the phenological phases of summer maize for the period 1981-2008 using field data from 18 agro-experimental stations in NCP (Fig. 1). The study also uses the Agricultural Production Systems Simulator (APSIM)-Maize model to determine the trends in summer maize phenology and their associations with climate change and cultivar shift in the plain. The main objectives of the study are (1) to characterize the temporal variability of the phenology of summer maize in NCP and (2) to find the potential causes of the characterized temporal variability. The results of the study will not only deepen our insight into the impacts of climate change and cultivar shift on crop production but will also enhance the adoption of high-yield cultivars to cope with warming and variable climatic conditions.

\section{Materials and methods}

\subsection{Study area}

As defined in this study, the NCP includes portions of Hebei, Henan, and Shandong provinces and Beijing and Tianjin municipalities. Climatic conditions and soil

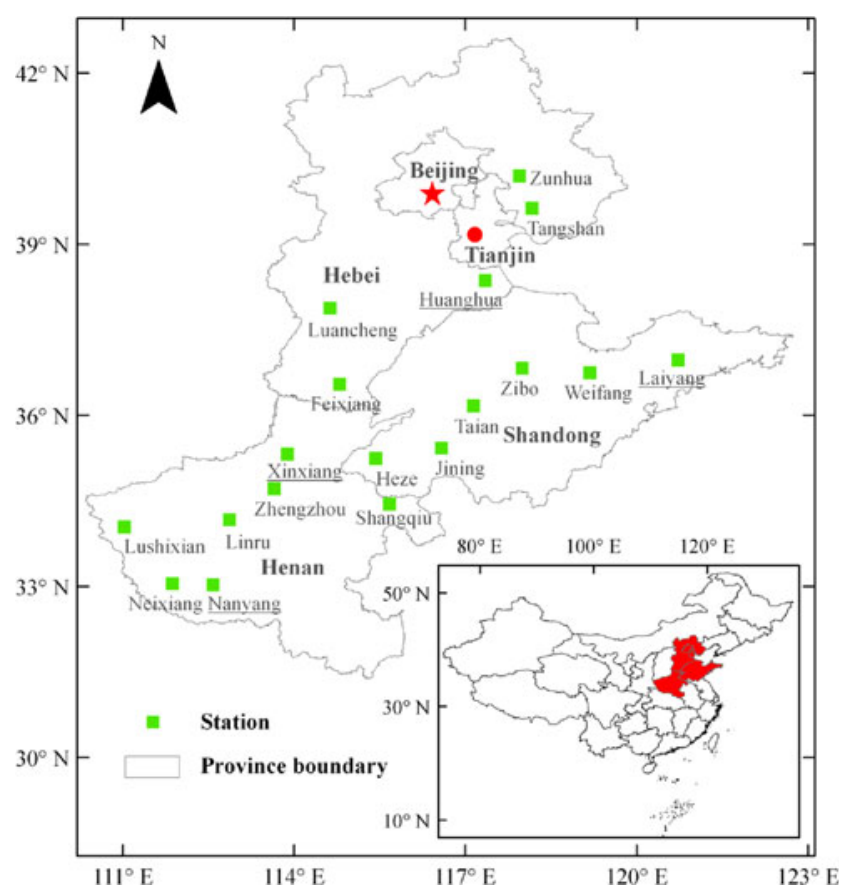

Fig. 1 A map depicting the geographical location of the study area (bottom right inset) and the locations of the agro-meteorological experiment stations used in the study (main map)

quality in the plain favor cultivation of summer maize and winter wheat. This study uses data from 18 agrometeorological experiment stations in the plain to analyze phenological trends in maize for the period 1981-2008 (Fig. 1). The stations are in typical maize production areas in the plain.

\subsection{Climate and crop data}

Maize phenological data for 1981-2008 at the national agrometeorological experimental stations are maintained by the Chinese Meteorological Administration (CMA). All the 18 stations record the dates of sowing, emergence, flowering, and maturity of maize. Four representative agrometeorological stations for which CMA also maintains historical daily whether data (including minimum and maximum temperature, sunshine duration, and precipitation) for 19812008 are used for detailed analysis. For each of the stations, the trend in solar radiation is estimated from observed sunshine hours using the Angstrom-Prescott equation (Angstrom 1924; Prescott 1940).

\subsection{APSIM-Maize model}

The APSIM is a cropping systems model developed by agricultural production systems research unit of Australia. APSIM is a component-driven model that concurrently runs several modules such as crop growth/development and soil water/ 
nitrogen dynamics (Keating et al. 2003; Yang et al. 2014). APSIM simulates phenological processes, biomass accumulation and partitioning, and leaf area index (LAI) as well as root, stem, leaf, and grain growth in daily time step from sowing to maturity.

Thermal time, which determines phase duration based on accumulated heat, is calculated in APSIM-Maize using the response function in Fig. 2. To minimize error associated with diurnal temperature variation, daily thermal time is calculated using average values of 3-hourly maximum and minimum air temperature interpolated from daily maximum and minimum temperature (Jones and Kiniry 1986). APSIM-Maize uses observed maize phenology data to define the days for each growth stage and daily minimum/maximum temperature to calculate thermal time for maize growth period in each station as given in Fig. 2.

APSIM-Maize defines 11 crop growth stages, and the start of each stage is determined by accumulated thermal time, except the sowing to germination stage that is driven by soil moisture. The phase between germination and emergence is determined by both thermal time and sowing depth; thus, this thermal time is assumed to be constant for every given station. The duration between emergence and flag leaf appearance is determined by total number of leaves on the plant and the rate of leaf appearance that is in turn determined by temperature. The total number of leaves equals that at germination plus that subsequently initiated until floral initiation. Hence, the time of floral initiation determines total leaf number and time of flag leaf appearance. If a cultivar is photoperiod sensitive, thermal development rate is sensitive to photoperiod between end of juvenile phase and floral initiation.

APSIM-Maize assumes that maize is a short day plant, with a longer phase between end of juvenile and initiation if photoperiod exceeds $12.5 \mathrm{~h}$. In this study, it is assumed that

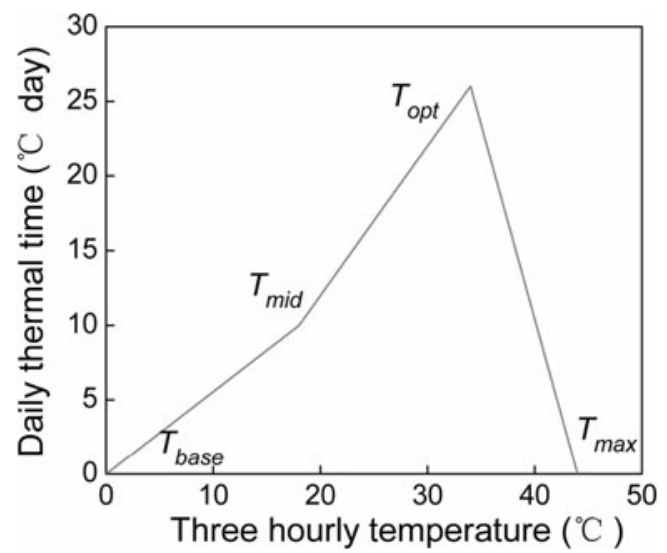

Fig. 2 Responses of daily thermal time to 3-hourly temperatures as required by APSIM-Maize model. $T_{\text {base }}$ is base temperature, $T_{\max }$ is maximum temperature, $T_{\text {opt }}$ is optimum temperature, and $T_{\text {mid }}$ is critical temperature for maize; development is denoted by a different linear response photoperiod sensitivity is constant within cultivars grown in 1981-2008. Based on the above assumption, total thermal time (TT) from emergence to end of juvenile stage (TT_emerg_to_endjuv) is defined as the observed change in cultivar TT during the vegetative period from emergence to flowering (Gv). Then, TT from flowering to maturity (TT_flower_to_maturity) is the observed change in cultivar TT during the reproductive period from flowering to maturity (Gr).

\subsection{Methods}

The trends in phenological processes of summer maize and durations of Gv and Gr are analyzed along with thermal time of the two growth periods (TT_emerg_to_endjuv and TT_flower_to_maturity) for 1981-2008. The time-variant trend in each variable is determined using linear regression model:

$Y_{i}=k X_{i}+b$

where $Y_{i}$ is the value of each variable in year $i ; k$ is the linear regression slope; $b$ is the slope intercept; and $X_{i}$ is the year $i$ $(i=1,2,3, \ldots, 28)$. Statistical significance is determined using the two-tailed $t$ test analysis at the 95 and $99 \%$ confidence levels.

Using APSIM-Maize, two model experiments (M1 and M2) are set up to determine the effects of climate change and cultivar shift on phenological processes and duration of growth period of maize (Table 1). For this purpose, four representative stations (Huanghua in Hebei Province, Xinxiang and Nanyang in Henan Province, and Laiyang in Shandong Province) are used (Fig. 1). In each of the four stations and model experiments, sowing date is fixed by average observed sowing dates for 1981-2008, which averaging approach reduces the effects of a single-year sowing date on subsequent phenology processes. Under experiment M1, the average observed phenology date for 19811985 is used to calculate TT for the two growth periods (TT_emerg_to_endjuv and TT_flower_to_maturity) (Table 1). This enables the detection of the trends in phenological events affected by climate change under M1 experiment. In experiment M2, TT_emerg_to_endjuv and TT_flower_to_maturity are calculated from observed phenology dates for 1981-2008 (Table 1). Here, it is possible to determine the trends in phenological events as affected by the combined effects of climate change and cultivar shift in the study area. Finally, the impacts of cultivar shift on maize phenology are determined using linear regression model as in Eq. (1). Therein $Y_{i}=M 2_{i}-M 1_{i}$, in which $M 1_{i}$ and $M 2_{i}$ are the values of each variable in year $i$ under experiments $\mathrm{M} 1$ and $\mathrm{M} 2$, respectively. 
Table 1 Details of the M1 and M2 model experiments used to determine the impacts of climate change and cultivar shift on summer maize phenology in North China Plain

\begin{tabular}{llcc}
\hline $\begin{array}{l}\text { Model } \\
\text { experiment }\end{array}$ & Sowing date & TT_emerg_to_endjuv & TT_flower_to_maturity \\
\hline M1 & $\begin{array}{c}\text { Based on average observed } \\
\text { sowing date for 1981- }\end{array}$ & $\begin{array}{c}\text { Based on average observed } \\
\text { phenology date for 1981- } \\
\text { 2008 }\end{array}$ & $\begin{array}{c}\text { Based on average observed } \\
\text { phenology date for 1981- } \\
1985\end{array}$ \\
M2 & $\begin{array}{c}\text { Based on average observed } \\
\text { sowing date for 1981- }\end{array}$ & $\begin{array}{c}\text { Based on observed phenology } \\
\text { date for 1981-2008 }\end{array}$ & $\begin{array}{c}\text { Based on observed phenology } \\
\text { date for 1981-2008 }\end{array}$ \\
& 2008 & & \\
\hline
\end{tabular}

\section{Results}

\subsection{Observed phenology date and growth period duration}

In NCP, summer maize is generally sown from late May (day of year (DOY) 146) at Zibo station to late June (DOY 179) at Zunhua station ((Table 2 and Fig. 3). As shown in Fig. 3, the average sowing date of maize for 1981-1993 is early May (DOY 123) at Tangshan station. However, it is delayed by 51 days to DOY 174 (late June) for 1994-2008. Also, the average sowing date of maize is DOY 134 (mid-May) for 1981-2000 at Zunhua station, delayed by 45 days to DOY 179 (late June) for 2001-2008. Among other factors, the date of emergence mainly depends on sowing date. In the study area, maize emerges 6-8 days after sowing (Table 2). Flowering is generally from late July to mid-August, and maturity is in mid to late September. As in Table 2, the periods from emergence to flowering $(\mathrm{Gv})$, flowering to maturity $(\mathrm{Gr})$, and emergence to maturity (Gw) are 48-59, 35-51, and 84 105 days, respectively.

Maize sowing date delays in ten stations during 1981-2008 and significantly in Zunhua, Tangshan, Weifang, and Jining stations. However, sowing date advances significantly in Zhengzhou and Zibo stations (Table 3). The trends in emergence date are consistent with those in sowing date. As in Table 3, there is no significant change in flowering date in most stations. The exception is for the significant delays in Zunhua, Tangshan, Weifang, Jining, and Taian stations and significant advances in Neixiang and Zibo stations. For 1981-2008, maturity date delays in 15 out of 18 stations and is significant in eight stations mostly in Shandong Province.

For 1981-2008, vegetative stage (Gv) duration shortens in 11 stations and significantly so in Zunhua, Tangshan, Neixiang, and Jining stations. The Gv prolongment is

Table 2 Averages of observed sowing (Sd), emergence (Ed), flowering $(\mathrm{Fd})$, and maturity $(\mathrm{Md})$ dates along with the durations of vegetative ( $\mathrm{Gv}$, emergence to flowering), reproductive (Gr, flowering to maturity), and

whole (Gw, emergence to maturity) growth periods of summer maize in the investigated 18 stations in North China Plain for the period 19812008

\begin{tabular}{|c|c|c|c|c|c|c|c|c|}
\hline Province & Station & $\mathrm{Sd}(\mathrm{DOY})$ & Ed (DOY) & Fd (DOY) & Md (DOY) & Gv (d) & Gr (d) & Gw (d) \\
\hline \multirow[t]{5}{*}{ Hebei } & Zunhua & $146 \pm 19.4$ & $153 \pm 18.3$ & $210 \pm 13.0$ & $258 \pm 14.6$ & $57 \pm 5.9$ & $49 \pm 3.4$ & $105 \pm 5.3$ \\
\hline & Tangshan & $154 \pm 26.5$ & $160 \pm 24.4$ & $215 \pm 16.8$ & $262 \pm 19.4$ & $54 \pm 7.8$ & $48 \pm 4.3$ & $102 \pm 7.0$ \\
\hline & Huanghua & $169 \pm 7.9$ & $175 \pm 8.0$ & $224 \pm 6.3$ & $259 \pm 7.4$ & $49 \pm 4.4$ & $35 \pm 3.1$ & $84 \pm 5.7$ \\
\hline & Luancheng & $157 \pm 4.2$ & $164 \pm 4.2$ & $215 \pm 4.1$ & $261 \pm 5.6$ & $52 \pm 3.2$ & $45 \pm 4.7$ & $97 \pm 5.5$ \\
\hline & Feixiang & $161 \pm 5.6$ & $169 \pm 6.0$ & $223 \pm 4.3$ & $264 \pm 5.5$ & $54 \pm 4.2$ & $41 \pm 3.5$ & $95 \pm 5.5$ \\
\hline \multirow[t]{7}{*}{ Henan } & Xinxiang & $156 \pm 5.9$ & $163 \pm 6.3$ & $214 \pm 4.1$ & $257 \pm 4.3$ & $51 \pm 3.8$ & $43 \pm 2.6$ & $94 \pm 4.6$ \\
\hline & Zhengzhou & $157 \pm 5.2$ & $163 \pm 4.8$ & $213 \pm 3.9$ & $254 \pm 4.1$ & $49 \pm 3.1$ & $42 \pm 2.6$ & $91 \pm 2.6$ \\
\hline & Shangqiu & $160 \pm 5.0$ & $166 \pm 4.8$ & $217 \pm 4.6$ & $259 \pm 6.3$ & $51 \pm 3.2$ & $42 \pm 2.7$ & $93 \pm 4.2$ \\
\hline & Linru & $154 \pm 3.8$ & $161 \pm 3.5$ & $212 \pm 3.1$ & $254 \pm 4.4$ & $51 \pm 2.9$ & $42 \pm 3.8$ & $93 \pm 5.2$ \\
\hline & Lushixian & $165 \pm 4.5$ & $172 \pm 4.7$ & $222 \pm 4.3$ & $273 \pm 5.7$ & $51 \pm 4.5$ & $51 \pm 4.8$ & $101 \pm 4.9$ \\
\hline & Neixiang & $155 \pm 5.6$ & $161 \pm 5.6$ & $211 \pm 6.0$ & $250 \pm 7.3$ & $50 \pm 3.6$ & $40 \pm 4.3$ & $90 \pm 5.2$ \\
\hline & Nanyang & $158 \pm 7.4$ & $164 \pm 6.5$ & $215 \pm 6.4$ & $257 \pm 9.0$ & $50 \pm 4.3$ & $42 \pm 4.3$ & $93 \pm 6.0$ \\
\hline \multirow[t]{6}{*}{ Shandong } & Laiyang & $161 \pm 13.2$ & $167 \pm 12.3$ & $220 \pm 7.1$ & $262 \pm 8.8$ & $53 \pm 6.3$ & $42 \pm 4.7$ & $95 \pm 7.2$ \\
\hline & Weifang & $148 \pm 7.8$ & $155 \pm 7.3$ & $214 \pm 5.3$ & $255 \pm 7.9$ & $59 \pm 4.4$ & $41 \pm 4.6$ & $100 \pm 6.9$ \\
\hline & Zibo & $146 \pm 4.9$ & $154 \pm 4.8$ & $210 \pm 3.6$ & $251 \pm 2.1$ & $56 \pm 2.9$ & $41 \pm 3.7$ & $97 \pm 4.6$ \\
\hline & Jining & $157 \pm 8.2$ & $163 \pm 8.1$ & $214 \pm 5.4$ & $255 \pm 4.9$ & $51 \pm 5.2$ & $41 \pm 3.3$ & $92 \pm 6.5$ \\
\hline & Heze & $158 \pm 6.4$ & $165 \pm 5.9$ & $216 \pm 3.9$ & $259 \pm 6.9$ & $52 \pm 4.7$ & $43 \pm 4.3$ & $94 \pm 7.1$ \\
\hline & Taian & $169 \pm 5.3$ & $176 \pm 5.0$ & $224 \pm 5.8$ & $265 \pm 7.6$ & $48 \pm 2.9$ & $41 \pm 4.3$ & $89 \pm 4.9$ \\
\hline
\end{tabular}

\pm number standard error of the difference (SED) of the respective variables, DOY day of year 


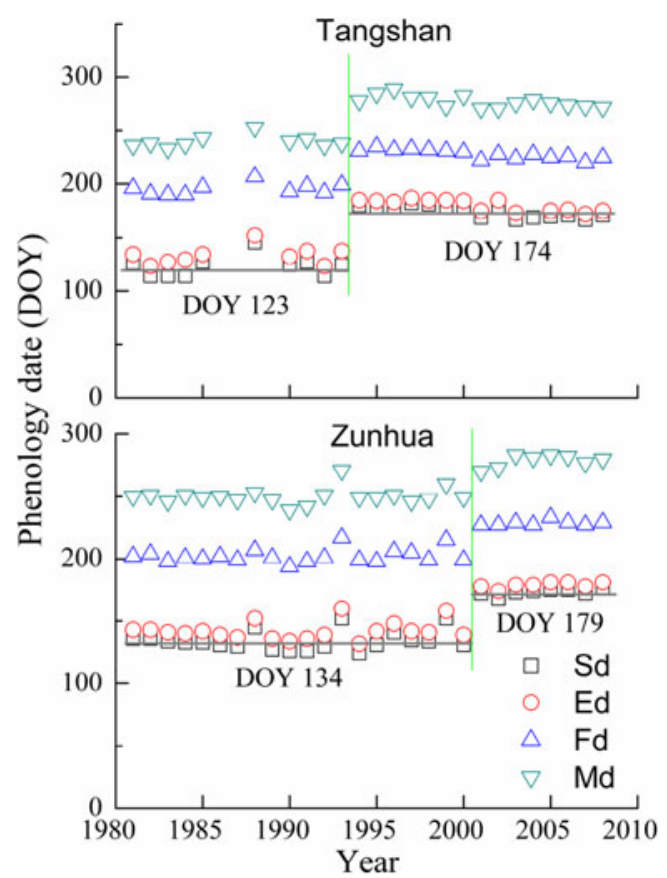

Fig. 3 Time series plots of field-observed dates of emergence $(E d)$, flowering $(F d)$, and maturity $(M d)$ of summer maize in Tangshan and Zunhua stations in North China Plain study area

significant in Feixiang, Zhengzhou, and Taian stations (Table 3). As in Table 3, maize reproductive stage (Gr) duration prolongs in all the stations, except in Zhengzhou and
Neixiang stations where it is unchanged and in Jining where it shortens though insignificantly. The Gr prolongment is significant in 12 stations. The duration of the whole growth period of maize $(\mathrm{Gw})$ prolongs in 13 stations and significantly so in 7 stations but shortens significantly in Zunhua, Tangshan, and Jining stations (Table 3).

Across the study area, there are no consistent trends in sowing date, emergence date, and flowering date of maize. However, a delay is noted in the trend in maturity date of maize in the region (Fig. 4). As a result of the change in maize phenology, the duration of the vegetative stage shortens in 1981-2008 across the study area. In contrast, the trend in the duration of reproductive stage and that in the whole growth period prolong in all the representative stations (Fig. 4).

\subsection{Thermal time for maize growth period}

As depicted in Fig. 5, total thermal time from emergence to end of juvenile stage (TT_emerg_to_endjuv) increases in Huanghua, Xinxiang, and Nanyang stations in 1981-2008. However, it significantly increases only in Huanghua station and insignificantly decreases in Laiyang station. Figure 5 also shows that TT_flower_to_maturity (total thermal time from flowering to maturity) drastically increases $\left(3.2-5.8^{\circ} \mathrm{C} /\right.$ year $)$ in the four representative stations in 1981-2008. This suggests that cultivar shift significantly increases cumulative thermal time of maize in NCP.
Table 3 Trends in observed sowing $(\mathrm{Sd})$, emergence $(\mathrm{Ed})$, flowering $(\mathrm{Fd})$, and maturity $(\mathrm{Md})$ dates along with the durations of vegetative (Gv, emergence to flowering), reproductive ( $\mathrm{Gr}$, flowering to maturity), and whole (Gw, emergence to maturity) growth periods of summer maize in the investigated 18 stations in North China Plain for the period 1981-2008

\begin{tabular}{|c|c|c|c|c|c|c|c|c|}
\hline Province & Station & $\begin{array}{l}\mathrm{Sd}(\mathrm{d} \\
\left.10 \mathrm{a}^{-1}\right)\end{array}$ & $\begin{array}{l}\mathrm{Ed}(\mathrm{d} \\
\left.10 \mathrm{a}^{-1}\right)\end{array}$ & $\begin{array}{l}\mathrm{Fd}(\mathrm{d} \\
\left.10 \mathrm{a}^{-1}\right)\end{array}$ & $\begin{array}{l}\mathrm{Md}(\mathrm{d} \\
\left.10 \mathrm{a}^{-1}\right)\end{array}$ & $\begin{array}{l}\mathrm{Gv}(\mathrm{d} \\
\left.10 \mathrm{a}^{-1}\right)\end{array}$ & $\begin{array}{l}\mathrm{Gr}(\mathrm{d} \\
\left.10 \mathrm{a}^{-1}\right)\end{array}$ & $\begin{array}{l}\text { Gw }(\mathrm{d} \\
\left.10 \mathrm{a}^{-1}\right)\end{array}$ \\
\hline \multirow[t]{5}{*}{ Hebei } & Zunhua & $18.0^{\mathrm{b}}$ & $17.1^{\mathrm{b}}$ & $12.0^{\mathrm{b}}$ & $13.4^{\mathrm{b}}$ & $-5.1^{\mathrm{b}}$ & 1.4 & $-3.7^{\mathrm{a}}$ \\
\hline & Tangshan & $23.7^{\mathrm{b}}$ & $21.6^{\mathrm{b}}$ & $14.8^{\mathrm{b}}$ & $17.4^{\mathrm{b}}$ & $-6.9^{b}$ & $2.6^{\mathrm{b}}$ & $-4.4^{\mathrm{b}}$ \\
\hline & Huanghua & -1.6 & -1.0 & 0.1 & 1.6 & 1.4 & $1.9^{\mathrm{b}}$ & $3.2^{\mathrm{b}}$ \\
\hline & Luancheng & 1.0 & 1.3 & 0.1 & $3.7^{\mathrm{b}}$ & -1.2 & $3.7^{\mathrm{b}}$ & $2.4^{\mathrm{a}}$ \\
\hline & Feixiang & -2.1 & -1.5 & 0.5 & 2.0 & $1.9^{\mathrm{a}}$ & 1.5 & $3.4^{\mathrm{b}}$ \\
\hline \multirow[t]{7}{*}{ Henan } & Xinxiang & 0.4 & 1.1 & 1.0 & 4.4 & -0.1 & $3.4^{\mathrm{b}}$ & $3.3^{\mathrm{a}}$ \\
\hline & Zhengzhou & $-2.4^{\mathrm{a}}$ & -1.5 & -0.1 & -0.1 & $1.4^{\mathrm{a}}$ & 0.0 & 1.4 \\
\hline & Shangqiu & -1.5 & -1.3 & -1.3 & 0.8 & 0.0 & $2.0^{\mathrm{b}}$ & $2.1^{\mathrm{a}}$ \\
\hline & Linru & -1.0 & -1.2 & -0.7 & 0.9 & 0.5 & $1.6^{\mathrm{a}}$ & 2.1 \\
\hline & Lushixian & 0.1 & 0.2 & -1.2 & -0.7 & -1.3 & 0.4 & -0.9 \\
\hline & Neixiang & -1.7 & -1.6 & $-3.2^{\mathrm{a}}$ & $-3.4^{\mathrm{a}}$ & $-1.6^{\mathrm{a}}$ & 0.0 & -1.7 \\
\hline & Nanyang & -0.3 & -0.4 & -1.2 & 0.8 & -0.9 & $2.0^{\mathrm{a}}$ & 1.2 \\
\hline \multirow[t]{6}{*}{ Shandong } & Laiyang & 3.5 & 3.6 & 1.6 & $5.8^{\mathrm{b}}$ & -2.0 & $4.2^{\mathrm{b}}$ & 2.2 \\
\hline & Weifang & $6.0^{\mathrm{b}}$ & $5.9^{\mathrm{b}}$ & $4.5^{\mathrm{b}}$ & $7.7^{\mathrm{b}}$ & -1.4 & $3.2^{\mathrm{b}}$ & 1.8 \\
\hline & Zibo & $-2.5^{\mathrm{a}}$ & $-2.6^{\mathrm{a}}$ & $-2.5^{\mathrm{b}}$ & $1.0^{\mathrm{a}}$ & 0.1 & $3.6^{\mathrm{b}}$ & $3.7^{\mathrm{b}}$ \\
\hline & Jining & $6.9^{\mathrm{b}}$ & $6.6^{\mathrm{b}}$ & $2.3^{\mathrm{a}}$ & 1.3 & $-4.3^{\mathrm{b}}$ & -1.1 & $-5.3^{\mathrm{b}}$ \\
\hline & Heze & 2.5 & $3.0^{\mathrm{a}}$ & 1.3 & $3.6^{\mathrm{b}}$ & -1.8 & $2.3^{\mathrm{a}}$ & 0.5 \\
\hline & Taian & 1.3 & 1.7 & $3.0^{\mathrm{a}}$ & $5.9^{\mathrm{b}}$ & $1.3^{\mathrm{a}}$ & $2.9^{\mathrm{b}}$ & $4.1^{\mathrm{b}}$ \\
\hline
\end{tabular}

$d 10 a^{-1}$ days per decade

${ }^{\text {a }}$ Significant trend at $5 \%$ probability level

${ }^{\mathrm{b}}$ Significant trend at $1 \%$ probability level 


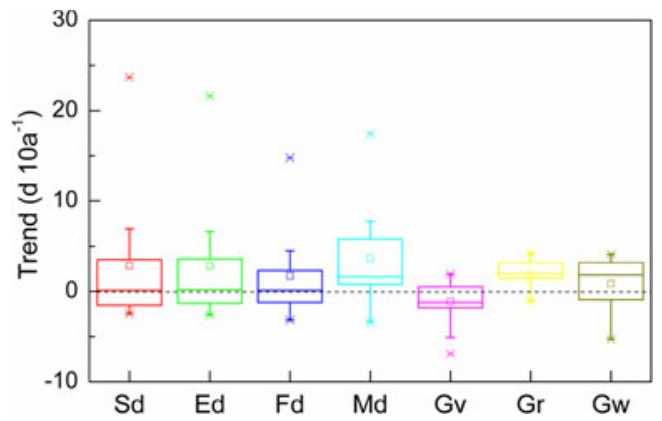

Fig. 4 Trends in summer maize phenology for 1981-2008 in the investigated stations in North China Plain. Note that $E d$ is emergence date, $F d$ is flowering date, $M d$ is maturity date, $G v$ is duration from emergence to anthesis, $G r$ is duration from anthesis to maturity, and $G w$ is duration from emergence to maturity

\subsection{Climate change, cultivar shift, and maize growth period}

As shown in Table 4, average minimum temperature for June to September (the main growing reason of summer maize in NCP) increases by $0.41-0.61{ }^{\circ} \mathrm{C}$ per decade in $1981-2008$. Note, however, that the increase in maximum temperature is insignificant.

As in Table 5 for M1 model, climate change advances flowering date of summer maize by $0.2-1.1$ days per decade in the study area. Like flowering date, summer maize maturity date advances in all the representative stations, and the trend is significant for Huanghua and Nanyang stations. Because the number of days of earlier maturity exceeds that of flowering, reproductive growth period $(\mathrm{Gr})$ shortens by $0.3-0.9$ days per decade, which is attributed to climate change (Table 5).

Under M2 combined effects of climate change and cultivar shift, flowering date delays in Huanghua and Xinxiang stations. It, however, advances in Nanyang and Laiyang stations respectively by 0.7 and 1.7 days per decade (Table 5 ). Also under M2, the trend in maturity date delays by 1.3-3.7 days per decade. Because of changes in the dates of flowering and maturity, Gr prolongs significantly, by 1.6-3.4 days per decade (Table 5).

From comparison of M1 and M2, flowering date delays in all the representative stations, except in Laiyang station. Also cultivar shift in 1981-2008 delays maturity date by 2.0 4.9 days per decade and prolongs Gr by 2.4-3.7 days per decade in the four representative stations (Table 5).

\section{Discussions}

In most of NCP, the typical cropping system is winter wheat and summer maize rotation (Xiao and Tao 2014). Summer maize is sown after winter wheat harvest, generally in mid to late June. But in the northern region of NCP, summer maize sown in June do not generally reach maturity in June because of insufficient cumulative thermal time. Hence in this study, maize is sown in early to mid May (called spring maize) in the period 1980-1993 in Tangshan station and in 1980-2000 in Zunhua station.
Fig. 5 Time series plots (19812008) of thermal time duration from emergence to end-ofjuvenile stage (TT_emerg to endjuv) and the duration from flowering to maturity (TT_ flower to maturity) of summer maize for the four representative stations in North China Plain. Single asterisk denotes significant trend at $5 \%$ probability level, and double asterisks denote significant trend at $1 \%$ probability level

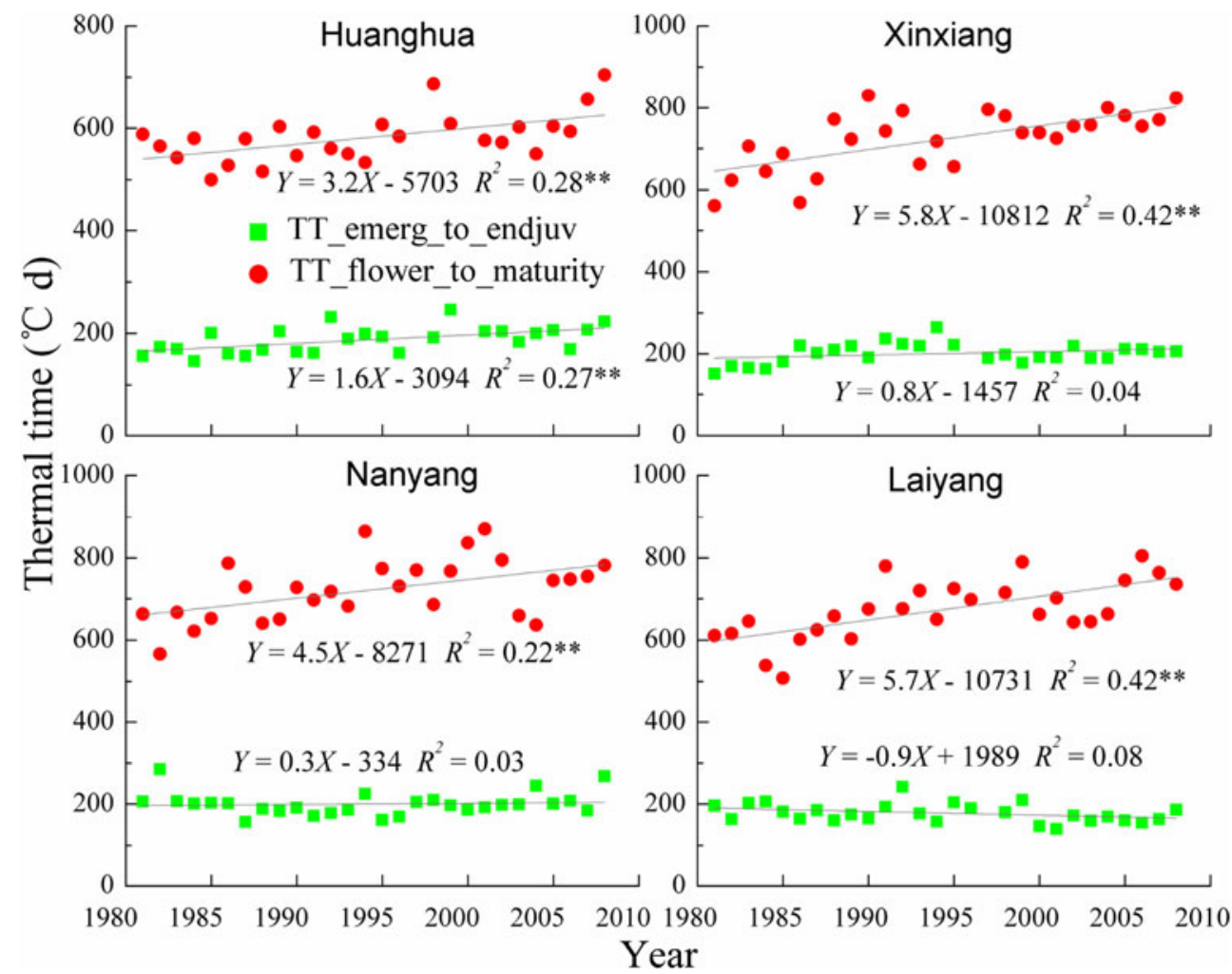


Table 4 Averages and trends of maximum and minimum temperatures for June (JUN), July (JUL), August (AUG), September (SEP), and for June to September (JUN_SEP) in the four representative stations in North China Plain for the period 1981-2008

\begin{tabular}{|c|c|c|c|c|c|c|c|c|c|c|c|}
\hline \multirow[t]{2}{*}{ Station } & \multirow[t]{2}{*}{ Temperature } & \multicolumn{5}{|c|}{ Maximum temperature } & \multicolumn{5}{|c|}{ Minimum temperature } \\
\hline & & JUN & JUL & AUG & SEP & JUN_SEP & JUN & JUL & AUG & SEP & JUN_SEP \\
\hline \multirow[t]{2}{*}{ Huanghua } & Average $\left({ }^{\circ} \mathrm{C}\right)$ & 30.9 & 31.5 & 30.5 & 26.8 & 29.9 & 19.7 & 22.8 & 22.0 & 16.5 & 20.3 \\
\hline & Trend $\left({ }^{\circ} \mathrm{C} 10 \mathrm{a}^{-1}\right)$ & 0.04 & 0.31 & 0.08 & 0.50 & 0.23 & $0.59^{\mathrm{b}}$ & $0.58^{\mathrm{a}}$ & $0.42^{\mathrm{a}}$ & $0.85^{\mathrm{b}}$ & $0.61^{\mathrm{b}}$ \\
\hline \multirow[t]{2}{*}{ Xinxiang } & Average $\left({ }^{\circ} \mathrm{C}\right)$ & 31.3 & 31.5 & 30.4 & 26.7 & 30.0 & 20.5 & 23.2 & 22.2 & 17.1 & 20.7 \\
\hline & Trend $\left({ }^{\circ} \mathrm{C} 10 \mathrm{a}^{-1}\right)$ & $0.55^{\mathrm{a}}$ & -0.06 & 0.01 & 0.39 & 0.22 & $0.57^{\mathrm{b}}$ & $0.37^{\mathrm{a}}$ & 0.25 & $0.47^{\mathrm{a}}$ & $0.41^{\mathrm{b}}$ \\
\hline \multirow[t]{2}{*}{ Nanyang } & Average $\left({ }^{\circ} \mathrm{C}\right)$ & 30.8 & 31.3 & 30.4 & 26.9 & 29.8 & 20.7 & 23.4 & 22.5 & 17.6 & 21.0 \\
\hline & Trend $\left({ }^{\circ} \mathrm{C} 10 \mathrm{a}^{-1}\right)$ & $0.60^{\mathrm{a}}$ & -0.01 & -0.03 & 0.33 & 0.22 & $0.74^{\mathrm{b}}$ & 0.39 & 0.17 & 0.39 & $0.42^{\mathrm{b}}$ \\
\hline \multirow[t]{2}{*}{ Laiyang } & Average $\left({ }^{\circ} \mathrm{C}\right)$ & 28.2 & 30.1 & 29.8 & 26.7 & 28.7 & 17.9 & 21.8 & 21.2 & 15.6 & 19.0 \\
\hline & Trend $\left({ }^{\circ} \mathrm{C} 10 \mathrm{a}^{-1}\right)$ & 0.08 & -0.06 & -0.10 & 0.29 & 0.05 & $0.68^{\mathrm{b}}$ & 0.16 & 0.27 & $0.73^{\mathrm{b}}$ & $0.46^{\mathrm{b}}$ \\
\hline
\end{tabular}

${ }^{\text {a }}$ Significant trend at $5 \%$ probability level

${ }^{\mathrm{b}}$ Significant trend at $1 \%$ probability level

The results show that these areas are not suitable for winter wheat/summer maize double cropping system. The regions are best suitable for single winter wheat cropping system (Xiao et al. 2013b). The warming temperatures in NCP seem to open a window of opportunity for cultivating summer maize/winter wheat cropping system in both Tangshan (since 1994) and Zunhua (since 2001) stations. The study further confirms that the increase in temperature since the $1980 \mathrm{~s}$ greatly influences cropping systems in China (Wang 1997; Yang et al. 2011).

As noted in this study, warmer climate speeds up crop development and thereby decreases the duration of maize growth period (Liu et al. 2013). In 1981-2008, maize growth season (which is mainly from June to September) experiences increasing warming conditions. The warming trend induces early flowering and maturity dates in most of the investigated stations. Then, the advances in flowering and maturity dates accordingly shorten maize growth phases, especially the reproductive phase.

The main mode of adaptation to warming climate investigated in this study is cultivar shift. This is because no significant or consistent trends are noted in other adaptation strategies to climate change (e.g., sowing date shift, Liu et al. 2013) in most of the investigated stations in study area. Therefore, the shift in maize sowing date is not considered a sufficient adaptation strategy in this study.

Based on the computed thermal time of the two growth phases of maize (Gv and Gr), cultivar shift in 1981-2008
Table 5 Simulated averages and trends of flowering date $(\mathrm{Fd})$ and maturity date $(\mathrm{Md})$ along with duration of reproductive growth period (Gr, flowering to maturity) of summer maize at the four representative stations in North China Plain for the period 19812008

\begin{tabular}{|c|c|c|c|c|c|c|c|}
\hline \multirow[t]{2}{*}{ Station } & \multirow{2}{*}{$\begin{array}{l}\text { Modeling } \\
\text { experiment }\end{array}$} & \multicolumn{2}{|l|}{$\mathrm{Fd}$} & \multicolumn{2}{|l|}{$\mathrm{Md}$} & \multicolumn{2}{|l|}{ Gr } \\
\hline & & $\begin{array}{l}\text { Average } \\
\text { (DOY) }\end{array}$ & 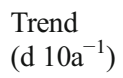 & $\begin{array}{l}\text { Average } \\
\text { (DOY) }\end{array}$ & $\begin{array}{l}\text { Trend } \\
\left({\left.\mathrm{d} 10 \mathrm{a}^{-1}\right)}^{-1}\right.\end{array}$ & $\begin{array}{l}\text { Average } \\
\text { (DOY) }\end{array}$ & 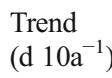 \\
\hline \multirow[t]{3}{*}{ Huanghua } & M1 & $220.6 \pm 2.2$ & -0.9 & $254.0 \pm 3.7$ & $-1.8^{\mathrm{a}}$ & $33.4 \pm 1.9$ & $-0.9^{\mathrm{a}}$ \\
\hline & M2 & $223.3 \pm 4.0$ & 1.8 & $259.1 \pm 6.0$ & $3.4^{\mathrm{b}}$ & $35.8 \pm 3.4$ & $1.6^{\mathrm{a}}$ \\
\hline & M2-M1 & $2.7 \pm 4.0$ & $2.5^{\mathrm{b}}$ & $5.1 \pm 6.5$ & $4.9^{\mathrm{b}}$ & $2.4 \pm 3.3$ & $2.4^{\mathrm{b}}$ \\
\hline \multirow[t]{3}{*}{ Xinxiang } & M1 & $210.2 \pm 1.8$ & -0.7 & $246.3 \pm 3.1$ & -1.0 & $36.1 \pm 1.7$ & -0.3 \\
\hline & M2 & $215.2 \pm 3.6$ & 0.4 & $257.5 \pm 7.4$ & $3.7^{\mathrm{a}}$ & $42.3 \pm 5.3$ & $3.4^{\mathrm{b}}$ \\
\hline & M2-M1 & $5.0 \pm 3.5$ & 1.1 & $11.0 \pm 7.3$ & $4.8^{\mathrm{b}}$ & $6.0 \pm 5.2$ & $3.7^{\mathrm{b}}$ \\
\hline \multirow[t]{3}{*}{ Nanyang } & M1 & $218.3 \pm 2.3$ & $-1.1^{\mathrm{a}}$ & $255.4 \pm 4.4$ & $-1.8^{\mathrm{a}}$ & $37.1 \pm 2.6$ & -0.7 \\
\hline & M2 & $215.4 \pm 4.2$ & -0.7 & $257.8 \pm 6.0$ & 1.9 & $42.3 \pm 4.2$ & $2.6^{\mathrm{b}}$ \\
\hline & M2-M1 & $-2.8 \pm 4.2$ & 0.4 & $2.4 \pm 6.6$ & $3.7^{\mathrm{a}}$ & $5.2 \pm 5.0$ & $3.3^{\mathrm{b}}$ \\
\hline \multirow[t]{3}{*}{ Laiyang } & M1 & $221.4 \pm 2.4$ & -0.2 & $257.4 \pm 3.8$ & -0.8 & $35.9 \pm 1.8$ & -0.6 \\
\hline & M2 & $219.7 \pm 4.4$ & -1.7 & $261.9 \pm 8.0$ & 1.3 & $42.1 \pm 5.3$ & $3.0^{\mathrm{a}}$ \\
\hline & M2-M1 & $-1.7 \pm 3.5$ & -1.6 & $4.5 \pm 7.2$ & $2.0^{\mathrm{a}}$ & $6.2 \pm 5.6$ & $3.6^{\mathrm{b}}$ \\
\hline
\end{tabular}

$d 10 a^{-1}$ day per decade, DOY day of year

${ }^{\text {a }}$ Significant trend at $5 \%$ probability level

${ }^{\mathrm{b}}$ Significant trend at $1 \%$ probability level 
increases thermal time requirements of reproductive stage. Long post-flowering period (Gr) suggests potential increases in grain-filling period and grain yield, which is a positive adaptation to the warming climate (Wang et al. 2012). Thus, latter cultivars with long growing periods and high TT increase resource use efficiency in the growing season, reducing the negative effects of climate change on crop production in the region (Wang et al. 2012; Xiao and Tao 2014; Tao et al. 2014).

The APSIM-Maize model analysis also suggests that maize cultivar shift delays maturity date and thereby prolongs reproductive growth stage (flowering to maturity) by $8-11$ days in 1981-2008. This is consistent with the conclusion reached by Liu et al. (2013) based on a study assessing the impact of cultivar shift on maize phenology in Northeast China. To a large extent, maize yield is determined by the length and time of various phenological phases (Tao and Zhang 2010). Although warming climate trend shortens the duration of Gv and Gr, cultivar shift significantly prolongs Gr (grain-filling duration, a critical yield formation stage) of summer maize in NCP. Thus, in terms of summer maize, cultivar shift is a vital adaptation strategy to warming climate. It is a factor used to ensure high yields of summer maize in the past decades.

Irrespectively, it is important to note that this study mainly analyzes the impacts of climate change and cultivar shift on phenological processes of summer maize in NCP. The effects of these two factors on maize yield are not directly analyzed in the study, suggesting the need for further studies in this direction. Also management practices such as irrigation and fertilization could affect crop phenology in many different ways. In fact, both irrigation and fertilizer requirements could increase under longer growth period cultivars. But while required irrigation is determined by the model simulation conditions, no nitrogen fertilizer deficiency is considered in this study.

\section{Conclusions}

This study shows that warming climate in recent decades shortens summer maize growth period in NCP. The results also suggest gradual adaptation of maize production in NCP to ongoing climate change by using cultivars with higher thermal requirement. As a result, the benefits of climate change (such as high heat) are exploited by adopting longer growth period cultivars. The findings of the study further underscore the complex responses and adaptation processes of crops to climate change in the study area. Sufficiently focused scientific studies are needed to develop suitably sustainable crop production and adaptation strategies in the study area and other main production regions across the globe.

Acknowledgments This study is supported by the National Natural Science Foundation of China (41401104). We are grateful to the anonymous reviews and editors for their inputs by way of insightful comments and suggestions during the manuscript review.

\section{References}

Angstrom A (1924) Solar and terrestrial radiation. Q J R Meteorol Soc 50: $121-126$

Chen G, Liu H, Zhang J, Liu P, Dong S (2012) Factors affecting summer maize yield under climate change in Shangdong Province in the Huanghuaihai Region of China. Int J Biometeorol 56:621-629

Craufurd PQ, Wheeler TR (2009) Climate change and the flowering time of annual crops. J Exp Bot 60:2529-2539

Estrella N, Sparks TH, Menzel A (2009) Trends and temperature response in the phenology of crops in Germany. Glob Chang Biol 13:17371747

IPCC (2013) Summary for policymakers. In: Stocker TF, Qin D, Plattner G-K, Tignor M, Allen SK, Boschung J, Nauels A, Xia Y, Bex V, Midgley PM (eds) Climate change 2013: the physical basis. Contribution of Working Group I to the Fifth Assessment Report of the Intergovernmental Panel on Climate Change. Cambridge University Press, Cambridge

Jones CA, Kiniry JR (1986) CERES Maize: a simulation model of maize growth and development, 1st edn. Texas A \& M University Press, College Station

Keating BA, Carberry PS, Hammer GL et al (2003) An overview of APSI $\mathrm{M}$, a model designed for farming systems simulation. Eur J Agron 18:267-288

Liu Y, Wang E, Yang X, Wang J (2010) Contributions of climatic and crop varietal changes to crop production in the North China Plain, since 1980s. Glob Chang Biol 16:2287-2299

Liu Z, Hubbard KG, Lin X, Yang X (2013) Negative effects of climate warming on maize yield are reserved by the changing of sowing date and cultivar selection in Northeast China. Glob Chang Biol 19: 3481-3492

Lobell DB, Schlenker W, Costa-Robert J (2011) Climate trends and global crop production since 1980. Science 333:616-620

Maddonni GA (2012) Analysis of the climatic constraints to maize production in the current agricultural region of Argentina - a probabilistic approach. Theor Appl Climatol 107:325-345

Mo X, Liu S, Lin Z, Guo R (2009) Regional crop yield, water consumption and water use efficiency and their responses to climate change in the North China Plain. Agric Ecosyst Environ 134:67-78

Olesen JE, Trnka M, Kersebaum KC, Skjelvag AO, Seguin B, PeltonenSainio P, Rossi F, Kozyra J, Micale F (2011) Impacts and adaptation of European crop production systems to climate change. Eur J Agron 34:96-112

Orlandi F, Ruga B, Romano B, Fornaciari M (2005) Olive flowering as an indicator of local climatic changes. Theor Appl Climatol 81:169 176

Porter JR (2005) Rising temperatures are likely to reduce crop yields. Nature 436:174

Prescott JA (1940) Evaporation from a water surface in relation to solar radiation. Trans Roy Soc S Aust 64:114-118

Tao F, Zhang Z (2010) Adaptation of maize production to climate change in North China Plain: quantify the relative contributions of adaptation options. Eur J Agron 33:103-116

Tao F, Yokozawa M, Xu Y, Hayashi Y, Zhang Z (2006) Climate changes and trends in phenology and yields of field crops in China, 19812000. Agric For Meteorol 138:82-92

Tao F, Zhang S, Zhang Z, Rotter RP (2014) Maize growing duration was prolonged across China in the past three decades under combined effects of temperature, agronomic management and cultivar shift. Glob Chang Biol. doi:10.1111/gcb.12684 
Wang FT (1997) Impact of climate change on cropping system and its implication for agriculture in China. Acta Meteorol Sin 11:407-415

Wang J, Wang EL, Yang X, Zhang F, Yin H (2012) Increased yield potential of wheat-maize cropping system in the North China Plain by climate change adaptation. Clim Chang 113:825-840

Xiao D, Tao F (2014) Contributions of cultivars, management and climate change to winter wheat yield in the North China Plain in the past three decades. Eur J Agron 52:112-122

Xiao D, Tao F, Liu Y, Shi W, Wang M, Liu F, Zhang S, Zhu Z (2013a) Observed changes in winter wheat phenology in the North China Plain for 1981-2009. Int J Biometeorol 57:275-285

Xiao D, Moiwo JP, Tao F, Yang Y, Shen Y, Xu Q, Liu J, Zhang H, Liu F (2013b) Spatiotemporal variability of winter wheat phenology in response to weather and climate variability in China. Mitig Adapt Strateg Glob Chang. doi:10.1007/s11027-013-9531-6

Yang X, Liu Z, Chen F (2011) The possible effect of climate warming on Northern limits of cropping system and crop yield in China. Agric Sci China 10:585-594

Yang Y, Liu D, Anwar MR, Zuo H, Yang Y (2014) Impact of future of climate change on wheat production in relation to plant-available water capacity in a semiarid environment. Theor Appl Climatol 115:391-410

Zhang T, Huang Y, Yang X (2013) Climate warming over the past three decades has shortened rice growth duration in China and cultivar shift have further accelerated the process for late rice. Glob Chang Biol 19:563-570 